\title{
Migration of carbonatite melts: insights from 4D tomography experiments under extreme conditions
}

\author{
ELENA GIOVENCO ${ }^{1}$, JEAN-PHILIPPE PERRILLAT ${ }^{1}$, \\ EGLANTINE BOULARD ${ }^{2}$, ANDREW KING ${ }^{3}$, NICOLAS \\ GUIGNOT $^{3}$ AND YANN LE GODEC ${ }^{2}$ \\ ${ }^{1}$ Laboratoire de Géologie de Lyon - Université Lyon 1 \\ ${ }^{2}$ Institut de minéralogie, de physique des matériaux et de \\ cosmochimie - CNRS \\ ${ }^{3}$ Synchrotron SOLEIL \\ Presenting Author: elena.giovenco@univ-lyon1.fr
}

Knowledge of the location and transport of magmas in the deep Earth is an important step toward the understanding of geochemical and geodynamical processes at depths. It comes as primary importance for carbon-rich melt as carbonate magmas impact the deep carbon cycle, which remains highly debated. Those carbonate magmas have unique properties, clearly distinct from the widespread silicate liquids, coming from their unpolymerized ionic structure. Due to the weak cohesion of carbonate molecules, these magmas have low viscosities $\left(<10^{-2}\right.$ Pa.s), small wetting angles $\left(<30^{\circ}\right)$, and a large buoyancy relative to surrounding mantle rocks. Hence, these liquids are expected to form interconnected networks and to be efficiently extracted even at low melt fractions. On a chemical point of view, this large connectivity along grains implies an important exchange surface that makes them highly reactive agents.

In this work, we investigated the dynamics and morphology of carbonate melt migration using real-time computed tomography (CT) imaging combining a synchrotron X-ray beam (PSICHE beamline, Synchrotron SOLEIL, France) and the UToPEc press, optimised for fast tomography. Starting materials were a barium carbonate nano-powder layer encapsulated between two polycrystalline silicate cylinders (olivine grains and sporadic iron oxides and pyroxenes). After cold compression up to $1.6-2.0$ $\mathrm{GPa}$, temperature was increased above the melting point of $\mathrm{BaCO}_{3}$ (i.e. $\mathrm{T}>800^{\circ} \mathrm{C}$ ) for $\mathrm{CT}$-imaging of liquid migration, with a few seconds resolution.

Kinetics of melt infiltration estimated from the time-lapsed CT-images exhibit the diffusive dynamics of capillary flow with a decrease of flow rates with time, and a positive dependence on temperature. The observed infiltration rates of $5.3-5.9 \mathrm{~mm} / \mathrm{h}$ confirm the high mobility of carbonate liquids relative to silicate ones. Chemical reactivity along specific grains was also observed at a time scale comparable with the melt flow. This point was further investigated using Raman and SEM on quenched samples in order to address the interplay between chemical reactions and melt transport physics. 